\title{
The effect of alkaline pretreatment on the thermal decomposition of hemp
}

\author{
Zoltán Sebestyén ${ }^{1}$, Zoltán May ${ }^{1}$, Kati Réczey ${ }^{2}$, Emma Jakab $^{1}$ \\ ${ }^{1}$ Institute of Materials and Environmental Chemistry, Chemical Research Center, \\ Hungarian Academy of Sciences, 1525, Budapest P.O. Box 17, Hungary \\ ${ }^{2}$ Department of Applied Biotechnology and Food Science, Budapest University of \\ Technology and Economics, Szent Gellért tér 4, Budapest, 1111, Hungary \\ e-mail:zoltan.sebestyen@chemres.hu
}

\section{Abstract}

The goal of this work was to study the effect of alkaline pretreatments on the thermal decomposition and composition of industrial hemp (Cannabis sativa L.) samples. Thermogravimetric/mass spectrometric measurements (TG/MS) have been performed, on untreated, hot water washed and alkali treated hemp samples. The main differences between the thermal decomposition of the samples are interpreted in terms of the different alkali ion contents which have been determined using inductively coupled plasma-optical emission spectroscopy (ICPOES) method. Principal Component Analysis (PCA) has been used to find statistical correlations between the data. Correlations have been obtained between the parameters of the thermal decomposition and the alkali ion content as well as the altered chemical structure of the samples. The differences in the thermal behaviour of the samples are explained by the different $\mathrm{K}^{+}$and $\mathrm{Na}^{+}$content and the changed structure of the hemicellulose component of the samples due to the pretreatments. The more alkali ions remain in the hemp samples after the alkali treatment, the more ash, char and lower molecular products are formed during thermal decomposition.

\section{Keywords}

hemp, alkaline pretreatment, thermogravimetry, thermal decomposition, principal component analysis

\section{Introduction}

Areas of the tropical and temperate zone, just like the main part of the Earth, possess very suitable local conditions to cultivate industrial hemp (Cannabis sativa L.). It has been cultivated for thousands of years, because its strong fibers take the humidity extremely well. Nowadays the hemp is utilized by the textile industry, producing technical textiles, sail-clothes and ropes. Recently, the application in fiber-reinforced composite materials $[1,2]$ and energetic utilization of the plant [3] have been studied extensively. Hemp can become one of the main substrates of the second generation bioethanol fermentation due to its high cellulose content [4-6]. Lignocellulosic natural materials after chemical and biological conversion can be used as a replacement of fossil fuels. 
Thermo- and biochemical processes are used for converting the non-food crops, plant and waste biomass into energy. Nowadays, the second generation lignocellulosic - bioethanol production represents an important research area [79]. The cellulose and hemicellulose component of biomass can be hydrolyzed to produce monomeric sugars, which can be fermented to ethanol. If cellulolytic enzymes are added to the biomass samples, the conversion of cellulose to sugar will be extremely slow since the cellulose is well protected by the matrix of hemicellulose and lignin. Therefore, pretreatment of the raw material is necessary to expose the cellulose or modify the pores in the material to allow the enzymes to penetrate into the fibres and hydrolyse the cellulose to monomeric sugars. Various alkaline pretreatments are used for breaking up the fibers $[10,11]$ as well as various fermentation techniques are studied to achieve higher ethanol yield [12, 13]. However, alkaline pretreatments lead to severe changes in the chemical composition of the samples.

It is difficult to establish the composition of biomass samples by conventional structure determination methods because the biopolymers can not be completely separated and dissolved. On the other hand, the thermochemical methods are suitable for examining the composition and thermal features of the biomass samples without separation of the components [14, 15]. More valuable information can be obtained about the composition of the biomass samples using coupled techniques, where the volatile decomposition products are monitored by a mass spectrometer [16-18] or an infrared spectrometer [19, 20].

The thermal degradation of various biomass samples has been studied extensively [21-24]. Several factors may influence the thermal behavior of plant materials. The inorganic ions are known to exert a great influence on the thermal decomposition of cellulose [25-33] and lignin [34-35] as well. Less information is available on the thermal decomposition of hemp. Rachini et al. [36] studied the effect of various treatments on the thermal stability of hemp fiber and concluded that $\mathrm{NaOH}$-treatment increases the thermal stability due to the reduction of pectin and hemicellulose component of hemp. Del Rio and coworkers [37-39] studied hemp lignin by pyrolysis-GC/MS and established that guaiacyl derivatives dominate among the pyrolysis products. Kristensen et al. [40] used multivariate analysis techniques to differentiate between various fibers on the basis of their pyrolysis products.

In this work, thermogravimetric/mass spectrometric (TG/MS) measurements have been carried out to study the thermal stability of hemp samples as well as the evolution rate and the yield of decomposition products. The alkali ion contents of the hemp samples were analyzed by ICP-OES system. The effects of the alkali ion contents have been studied on the thermal behavior of 17 samples with the goal of finding correlations between the alkali ion content and the thermal behavior in a relatively wide concentration range.

\section{Experimental}

\section{Materials}

The whole dry stems of hemp (Cannabis sativa L.) were ground by a cutting mill to $<1 \mathrm{~mm}$ and further ground to $<0.12 \mathrm{~mm}$ particle size. The investigated materials were untreated, washed and various alkaline pretreated hemp samples. The alkaline pretreatments were carried out in an autoclave on $40 \mathrm{~g}$ hemp samples 
using $360 \mathrm{ml}$ alkali (sodium or potassium) solutions. The alkali concentration, temperature and time of the pretreatments were varied and 9 different treatment conditions were applied. After cooling down, the samples were filtered and washed with boiling water 3-4 times. The original and 2 alkali treated samples were washed with $60^{\circ} \mathrm{C}$ hot water for 2 hours, filtered and dried at $105^{\circ} \mathrm{C}$. The pretreatment conditions are summarized in Table 1.

\section{Methods}

\section{$T G / M S$}

The TG/MS system consists of a modified Perkin-Elmer TGS-2 termobalance and a Hiden HAL quadrupole mass spectrometer. About $3 \mathrm{mg}$ samples were measured in argon atmosphere at a flow rate of $140 \mathrm{ml} \mathrm{min}^{-1}$. The samples were heated at a rate of $10^{\circ} \mathrm{C} \mathrm{min}^{-1}$ from 25 to $900^{\circ} \mathrm{C}$ in a platinum sample pan. The evolved products were introduced through a glass lined metal capillary heated at $300^{\circ} \mathrm{C}$ into the ion source of the mass spectrometer which was operated at $70 \mathrm{eV}$ electron energy. The mass range of 15-155 Da was scanned at every 25 s excluding the main ions of the argon carrier gas. The ion intensities were normalized to the sample mass and to the intensity of the ${ }^{38} \mathrm{Ar}$ isotope of the carrier gas.

\section{ICP-OES}

About $1 \mathrm{~g}$ samples were ashed at $520^{\circ} \mathrm{C}$ in a furnace. The amounts of the ashes have been determined using a CEN/TS $14775 \mathrm{EU}$ standard method. The ashes were fused at $920^{\circ} \mathrm{C}$ with a fusion blend $\left(\mathrm{Li}_{2} \mathrm{~B}_{4} \mathrm{O}_{7}: \mathrm{LiBO}_{2}, 2: 1\right)$ and digested by $25 \mathrm{~cm}^{3} 33 \% \mathrm{HNO}_{3}$. The $\mathrm{K}^{+}$and $\mathrm{Na}^{+}$contents of the samples were determined by a Spectro Genesis ICP-OES equipment (Spectro Analytical Instruments) with axial plasma observation.

\section{Results and discussions}

\section{Alkali ion contents of the samples}

Table 1 shows the types of treatments and the characterization of the hemp samples. The experiments of the untreated and two alkali-treated samples have been repeated to verify the repeatability of the applied methods. The volatile content and the char yield were determined by thermogravimetry heating the samples up to $900^{\circ} \mathrm{C}$. The char yield of the untreated hemp samples were 17-19 $\%$, while the alkali-treated samples produced 23-26\% char, which can be explained by the catalytic effect of the alkali ions on the char formation [27]. The alkali ion contents of the samples were determined in order to distinguish between the effect of alkali pretreatment on the composition of hemp and the impact of the residual alkali ions on the thermal behavior of the samples. The untreated samples contained 4-5 thousands ppm potassium and 1-3 hundreds ppm sodium ions. The alkali treatment resulted in an increased alkali ion content in spite of the washing the samples 3-4 times by boiling water. The potassium content of the hemp samples was about doubled by the $\mathrm{KOH}$ treatments, while the amount of the 
sodium ions was not changed significantly. As an effect of the $\mathrm{NaOH}$ treatments, the sodium ion contents were increased several times comparing to the untreated samples, while the majority of the potassium ions were removed or substituted for sodium ions. The prolonged washing with hot water $\left(60^{\circ} \mathrm{C}\right)$ for 2 hours appeared to be very effective in eliminating the alkali ion contents of the samples as suggested previously [41]. About $98 \%$ of the potassium ion content and about 40 $\%$ of the sodium ion content of the untreated hemp sample were removed by the washing. The alkali ion contents of the hot-water washed $\mathrm{NaOH}$ or $\mathrm{KOH}$ treated samples were also decreased considerably. The hot-water washing reduced not only the alkali ion content, but the total ash content was diminished by about half.

Table 1 Characterization of the hemp samples studied.

\begin{tabular}{clccccc}
\hline No. & Samples and treatments & $\begin{array}{c}\text { Volatiles } \\
\text { /\% }\end{array}$ & $\begin{array}{c}\text { Char } \\
\text { /\% }\end{array}$ & $\begin{array}{c}\text { Ash } \\
\text { content } \\
\text { /\% }\end{array}$ & $\begin{array}{c}\mathbf{K}^{+} \text {content } \\
\text { /ppm }\end{array}$ & $\begin{array}{c}\mathbf{N a}^{+} \text {content } \\
\text { /ppm }\end{array}$ \\
\hline 1 & Untreated, ground to $<1 \mathrm{~mm} / 1$ & 81.0 & 19.0 & 2.41 & 4907 & 107 \\
2 & Untreated, ground to <1mm / 2 & 81.1 & 18.9 & 2.13 & 4656 & 173 \\
3 & Untreated, ground to & 82.6 & 17.4 & 2.14 & 4397 & 277 \\
& $<0.12 \mathrm{~mm}$. & 87.6 & 12.4 & 1.04 & 95 & 64 \\
4 & Washed with $60^{\circ} \mathrm{C}$ water & & & & \\
& $2 \% \mathrm{NaOH}, 120^{\circ} \mathrm{C}, 2$ hours and & 86.7 & 13.3 & 1.80 & 65 & 347 \\
& washed with $60^{\circ} \mathrm{C}$ water & & & & & \\
6 & $2 \% \mathrm{KOH}, 120^{\circ} \mathrm{C}, 2$ hours and & 86.5 & 13.5 & 1.64 & 644 & 99 \\
7 & washed with $60^{\circ} \mathrm{C}$ water & & & & & 7341 \\
8 & $2 \% \mathrm{NaOH}, 120^{\circ} \mathrm{C}, 2$ hours $/ 1$ & 76.4 & 23.6 & 3.43 & 782 & 7934 \\
9 & $2 \% \mathrm{NaOH}, 120^{\circ} \mathrm{C}, 2$ hours $/ 2$ & 74.0 & 26.0 & 3.54 & 900 & 8658 \\
10 & $1 \% \mathrm{NaOH}, 120^{\circ} \mathrm{C}, 1$ hour & 74.2 & 25.8 & 3.57 & 840 & 5706 \\
11 & $1 \% \mathrm{NaOH}, 120^{\circ} \mathrm{C}, 2$ hours & 76.1 & 23.9 & 2.86 & 1001 & 5736 \\
12 & $1 \% \mathrm{NaOH}, 140^{\circ} \mathrm{C}, 1$ hour & 75.7 & 24.2 & 3.05 & 1095 & 5875 \\
13 & $2 \% \mathrm{KOH}, 120^{\circ} \mathrm{C}, 2$ hours $/ 1$ & 76.1 & 23.9 & 2.62 & 873 & 266 \\
14 & $2 \% \mathrm{KOH}, 120^{\circ} \mathrm{C}, 2$ hours $/ 2$ & 76.6 & 24.4 & 3.23 & 9131 & 274 \\
15 & $1 \% \mathrm{KOH}, 120^{\circ} \mathrm{C}, 2$ hours & 76.5 & 23.5 & 2.74 & 8474 & 127 \\
16 & $1 \% \mathrm{KOH}, 140^{\circ} \mathrm{C}, 2$ hours & 77.2 & 22.8 & 2.33 & 5789 & 266 \\
17 & $1 \% \mathrm{KOH}, 120^{\circ} \mathrm{C}, 1$ hour & 74.3 & 25.7 & 2.91 & 9208 & 257 \\
\hline
\end{tabular}

\section{TG/MS results}

Figs. 1a and $\mathrm{b}$ show the thermogravimetry (TG) and derivative thermogravimetry (DTG) curves of selected hemp samples, respectively. As Fig. 1a shows, the char yield of the hemp samples presents a twofold difference. The lowest yields of the carbonaceous residue were produced during the decomposition of the washed and the alkaline treated-washed samples, which can be explained by the lowest amounts of potassium and sodium ions as a result of the hot water washing (Table 1). The highest char yield was formed during the decomposition of the alkaline treated samples because the formation of the carbonaceous residue was promoted by the relatively high potassium and sodium ion content. It is in agreement with the literature data describing the large effect of alkali ions on the cellulose decomposition [25-27, 31, 32]. 

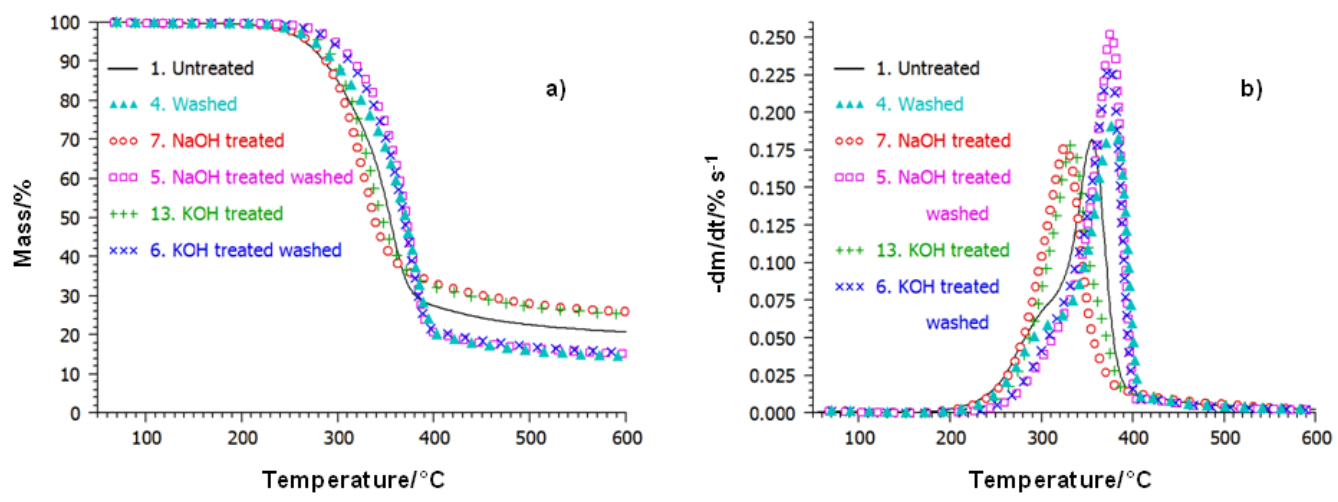

Fig. $1 \mathrm{a}-\mathrm{TG}$ and $\mathrm{b}-\mathrm{DTG}$ curves of untreated and pretreated hemp samples at $10^{\circ} \mathrm{C} \mathrm{min}^{-1}$ heating rate in argon atmosphere

The main DTG peak of the hemp samples (Fig. 1b) can be attributed to the decomposition of cellulose, and the shoulder at about $300^{\circ} \mathrm{C}$ originates from the hemicellulose decomposition. The lignin decomposition is not separated on the DTG curve due to its low decomposition rate and a broad temperature range of decomposition (from $250^{\circ} \mathrm{C}$ to $500^{\circ} \mathrm{C}$ ). The DTG curves show that the thermal decomposition of the washed alkaline treated samples starts at the highest temperature and the decomposition rate of these hemp samples has the highest maximum $\left(\mathrm{DTG}_{\max }\right)$ too. The thermal decomposition of the untreated sample starts at the lowest temperature and the curve have a shoulder characteristic of the hemicellulose decomposition. This shoulder on the other DTG curves disappears due to the alkaline treatment indicating that the structure of hemicellulose has changed. Since the hemicellulose content of the alkaline treated samples did not change significantly [42] we assume that the side groups (e.g. acetyl groups) of the hemicellulose were removed by the alkaline washing. Thus the thermal stability of the hemicellulose was increased and it decomposes in a similar temperature range as cellulose. This assumption explains that the washed alkaline treated hemp has higher DTG peak than the washed untreated sample in spite of the similar alkali ion content.

Further information is given by the mass spectrometric curves about the reactions of the thermal decomposition. As Fig. 2 illustrates, the most important decomposition products of the untreated and $\mathrm{NaOH}$-treated hemp samples at the lower mass range are methane $(\mathrm{m} / \mathrm{z}, 15)$, water $(\mathrm{m} / \mathrm{z} 18)$, carbon monoxide $(\mathrm{m} / \mathrm{z}$ 28), carbon dioxide $(\mathrm{m} / \mathrm{z} 44)$ and formaldehyde $(\mathrm{m} / \mathrm{z} 30)$, while acetic acid and hydroxyacetaldehyde $(\mathrm{m} / \mathrm{z}, 60)$, furanone $(\mathrm{m} / \mathrm{z}, 84)$ and furfural $(\mathrm{m} / \mathrm{z}, 95$ and 96$)$ can be monitored at the higher mass range. Unfortunately, higher molecular mass products (e.g., levoglucosan and phenol derivatives) can not be detected by TG/MS due to condensation. 

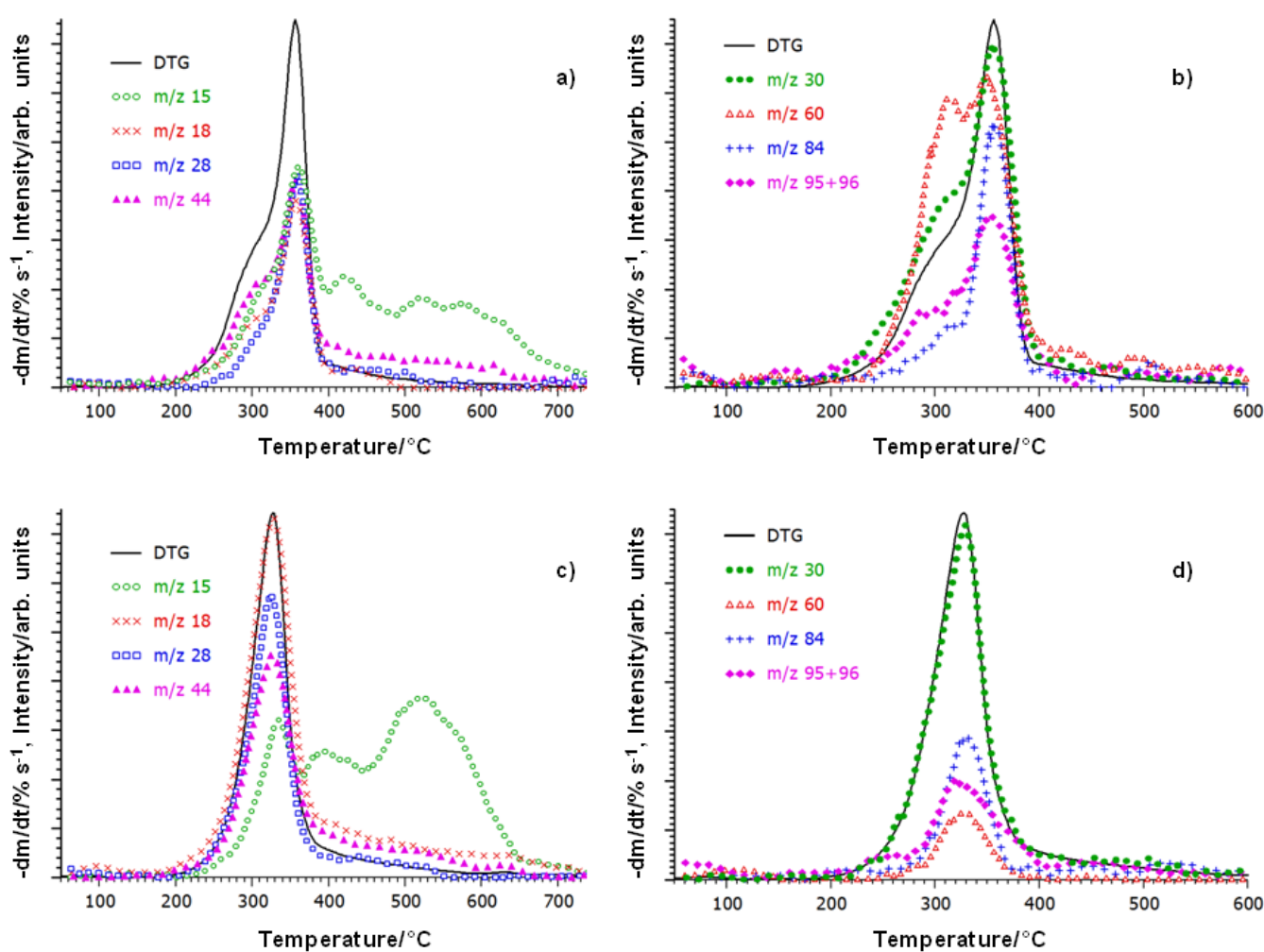

Fig. 2 DTG and mass spectrometric curves of a, b - untreated (Sample No. 1.) and c, d - NaOH treated (Sample No. 7.) samples

The yield of the lower mass products is increased, while the intensity of the higher mass products is reduced in the $\mathrm{NaOH}$-treated sample, which has elevated sodium ion content. The methane formation is monitored by its fragment ion $(\mathrm{m} / \mathrm{z} 15)$ because the molecular ion $(\mathrm{m} / \mathrm{z}, 16)$ is biased by the fragment ions of the main decomposition products (water, carbon monoxide, carbon dioxide). The methyl ion can be formed by different reactions. The first peak (at about $330^{\circ} \mathrm{C}$ ) can be attributed to the formation of fragment ions from various decomposition products; the second peak (at about $440^{\circ} \mathrm{C}$ ) represents mostly the methane evolution from lignin [35] and the third one (at $540^{\circ} \mathrm{C}$ ) is due to the charring reactions. The intensities of water and carbon monoxide have been doubled by the $\mathrm{NaOH}$ treatment. In Figs. 2a-b a shoulder can be seen on the MS-curves, which can be attributed to the decomposition of the hemicellulose component of hemp. The most remarkable effect of the alkaline treatment is the lack of the partially separated hemicellulose peak on the DTG and MS curves. Recently, Rachini et al. concluded that the pectin content of hemp degrades at about $235^{\circ} \mathrm{C}$. We do not see separated DTG peak at this temperature, but the formaldehyde curve presents a shoulder at around $240^{\circ} \mathrm{C}$, which is possible to be originated from the side groups of pectin. This shoulder also disappeared at the evolution curve of formaldehyde from the alkali-treated samples.

There are two peaks at $m / z, 60$ from the untreated hemp sample (Fig. 2c). The first one (at about $320^{\circ} \mathrm{C}$ ) can be attributed to acetic acid originating from the hemicellulose component of the samples, while the second one (at about $380^{\circ} \mathrm{C}$ ) represents hydroxyacetaldehyde evolving from the cellulose part [43]. The intensity of $\mathrm{m} / \mathrm{z} 60$ ion is reduced to one half. The first peak attributed to acetic 
acid disappeared confirming the hypothesis that the acetyl groups of hemicellulose were eliminated during the alkaline treatment.

It is well-known that alkali ions have significant influence on the thermal decomposition of cellulose [25-27] and lignin [34, 35], however, the concentration effect is less studied. In this work, we examined the effect of $\mathrm{K}^{+}$and $\mathrm{Na}^{+}$-ions in a wide range of concentration. It was not possible to remove these ions completely from the hemp samples, hence we could not study their influence separately. Therefore we used the sum of the molar amounts of $\mathrm{K}^{+}$- and $\mathrm{Na}^{+}$-ions in the plots assuming that they have similar impacts on the decomposition mechanisms. Fig. 3 presents the change of four thermogravimetric parameters as a function of the alkali ion contents of hemp samples. Figs. $3 \mathrm{a}$ and $3 \mathrm{~b}$ show the temperature of the maximum decomposition rate $\left(\mathrm{T}_{\text {peak }}\right)$ and the temperature of the end of decomposition ( $\mathrm{T}_{\mathrm{end}}$ ), which was determined by extrapolation of the DTG peak. These parameters are characteristic of the cellulose decomposition and they decrease with increasing $\mathrm{K}^{+}$and $\mathrm{Na}^{+}$ion content. . We can conclude that the changes of the TG parameters are very large in the lower concentration range $(0$ $0.2 \mathrm{mmol} \mathrm{g}^{-1}$, while the additional alkali ions have decreasing effects on the decomposition.

As Fig. 3c illustrates, the yield of the carbonaceous residue (char) is also strongly influenced by the alkali ion content. The more alkali ion is present in the sample, the more char is formed because the decomposition mechanism of cellulose and lignin has been changed by the presence of the alkali ions. The largest alteration can be observed in the $0-0.2 \mathrm{mmol} \mathrm{g}^{-1}$ concentration range similarly to the DTG parameters.
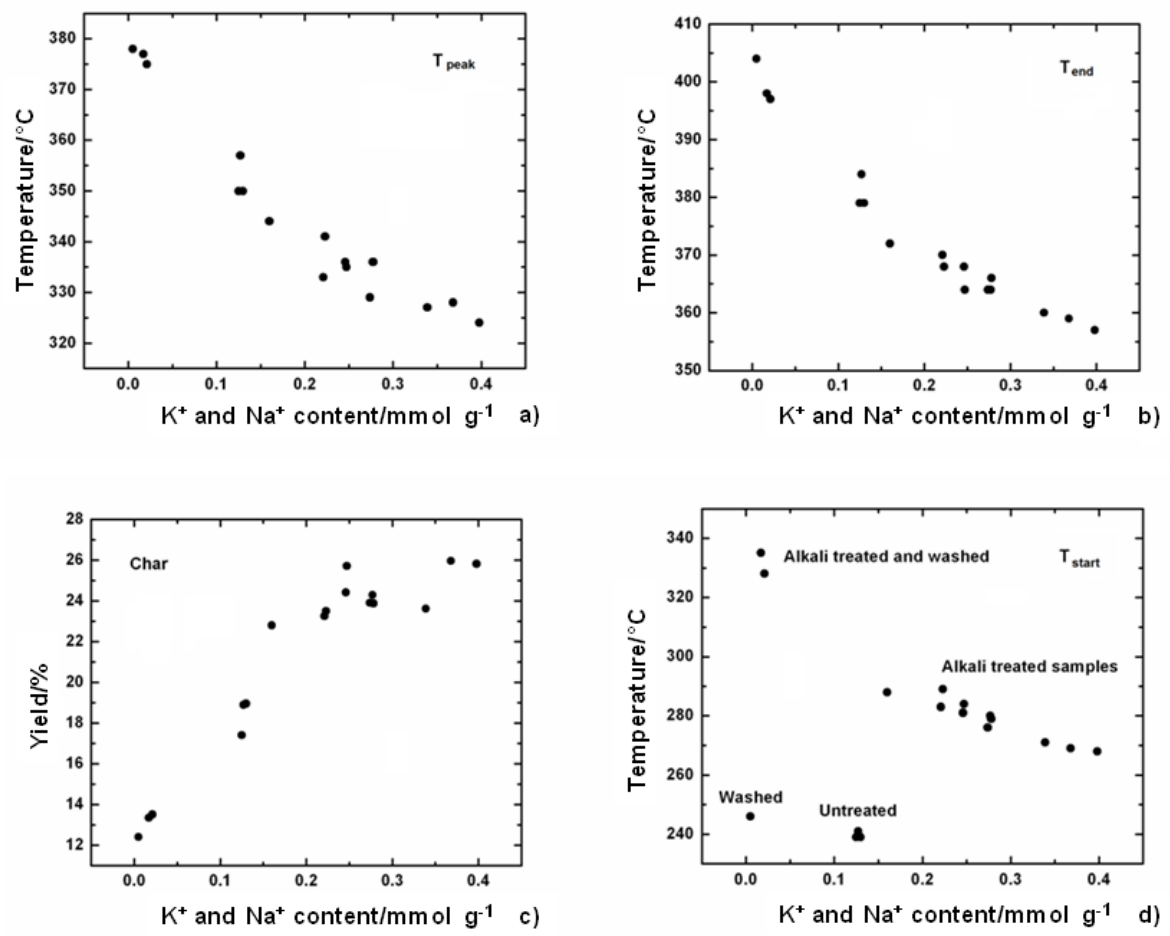

Fig. 3 Thermogravimetric parameters as a function of the alkali ion content of the samples (a temperature of the maximum decomposition rate, $\mathrm{b}$ - temperature of the end of decomposition, $\mathrm{c}-$ yield of carbonaceous residue, $\mathrm{d}$ - starting temperature of the decomposition) 
Fig. 3d shows the starting temperature of the decomposition $\left(\mathrm{T}_{\text {start }}\right)$, which was determined by extrapolation of the DTG peak. As discussed above, the shoulder on the DTG curves (Fig. 1b) can be attributed to hemicellulose decomposition. Therefore the starting temperature of the decomposition also belongs to the hemicellulose decomposition, which is about $240^{\circ} \mathrm{C}$ in the washed and untreated hemp samples (Fig. 3d). The shoulder of the DTG curves disappeared in the alkaline treated samples (Fig. 1b) and the beginning of the decomposition shifted to higher temperatures $\left(270-340^{\circ} \mathrm{C}\right)$ indicating the modification of hemicellulose structure. Nevertheless, the alkali ion content have similar effect on the beginning temperature of decomposition as on the other $\mathrm{T}$ parameters, but the alkali-treated samples differs from the untreated samples due to the altered hemicellulose structure upon alkaline treatment.

The thermogravimetric parameters imply that the increased alkali ion content of the hemp samples alters the decomposition mechanism. This conclusion is confirmed by the yield of the decomposition products. The char yield and the intensity of the lower molecular mass products increased, while less products of high molecular mass were formed (Fig. 2.). Fig. 4 shows the integrated intensity of a few products as a function of the alkali ion content of the samples. As Fig. 4a-b illustrate the yield of methane $(\mathrm{m} / \mathrm{z}, 15)$ and water $(\mathrm{m} / \mathrm{z}, 18)$ increased with the increasing alkali ion content more prominently in the $0-0.2 \mathrm{mmol} \mathrm{g}^{-1}$ alkali ion concentration range.
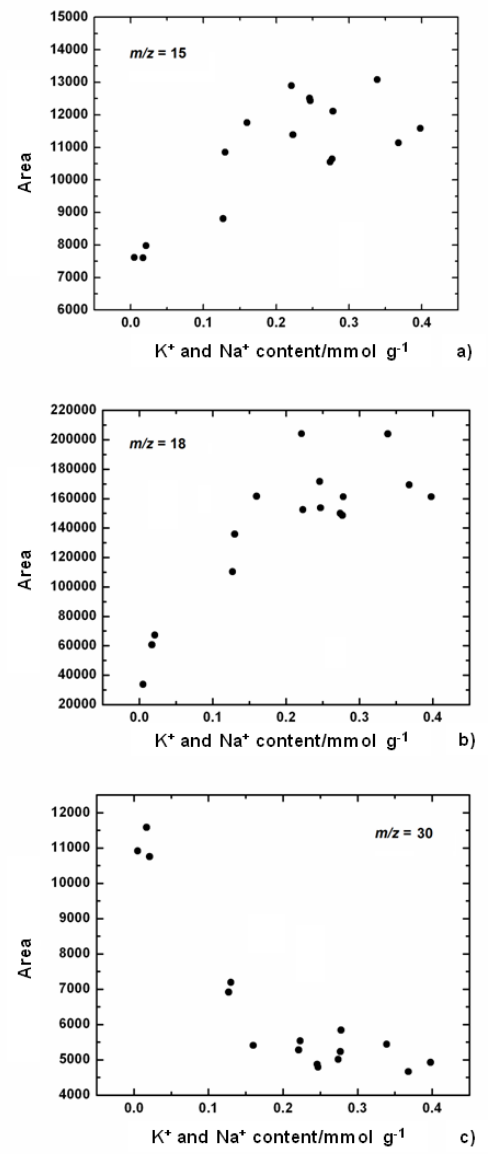

Fig. 4 Mass spectrometric intensities as a function of the alkali ion contents of the samples (a methane, $\mathrm{b}$ - water, $\mathrm{c}$ - formaldehyde) 
The treated samples of high alkali ion content release about ten times higher yield of water than the washed sample, which contains the least amounts of alkali ions. On the other hand, the amount of the formaldehyde (Fig. 4c) is half in the case of alkali treated samples than that from the untreated or washed samples.

\section{PCA calculations}

Principal component analysis has been used to reveal further correlations between TG/MS data as well as the $\mathrm{K}^{+}$and $\mathrm{Na}^{+}$contents of the samples. Two calculations have been carried out by the PCA. In the first one, the TG parameters $\left(\mathrm{T}_{\text {peak }}\right.$, $\mathrm{DTG}_{\max }, \mathrm{T}_{1 \%}, \mathrm{~T}_{\text {start }}, \mathrm{T}_{\text {end }}$, Char yield) and the $\mathrm{K}^{+}$and $\mathrm{Na}^{+}$contents have been used as input data to find similarities and differences between the original and treated hemp samples (Table 1 and Fig. 5a-b). Beside the extrapolated $\mathrm{T}_{\text {start value, the }}$ beginning of the decomposition was also characterized by $\mathrm{T}_{1 \%}$, which belongs to the temperature of $1 \%$ mass loss. $\mathrm{T}_{\text {start }}$ is characteristic of the beginning of hemicellulose decomposition, while $\mathrm{T}_{1 \%}$ reflects the evaporation of extractive components and the decomposition of pectin that occurs at lower temperature than the hemicellulose decomposition. In the PCA calculation the first principal component (Factor 1) described $67.6 \%$ of the total variance of the thermogravimetric data and the second component (Factor 2) described $28.8 \%$ of the total variance. The score plot (Fig. 5a) shows that the thermogravimetric characteristics of the $\mathrm{NaOH}$ or $\mathrm{KOH}$ treated hemp samples clearly differ from the others. The first principal component separates the hot-water washed samples from the others, while the second principal component can be attributed to the effect of the alkali-treatments. The thermogravimetric characteristics of the washed $\mathrm{NaOH}$ - or $\mathrm{KOH}$-treated samples differ to a great extent from that of the washed untreated hemp samples. Since the alkali content of these samples are rather similar, the different thermal behaviour can be explained by the assumption that the alkali treatment caused chemical changes in the composition of hemp. The loading plot (Fig. 5b) suggests that the char yield, $\mathrm{T}_{\text {peak }}$ and $\mathrm{T}_{\text {end }}$ correlates mostly with the $\mathrm{K}^{+}$and $\mathrm{Na}^{+}$content of the samples. These variables and $\mathrm{DTG}_{\max }$ contribute mostly to the differences between the washed and unwashed samples. These DTG parameters can be attributed to the cellulose decomposition. The temperatures of the start of the decomposition $\left(\mathrm{T}_{\text {start }}\right.$ and $\left.\mathrm{T}_{1 \%}\right)$ contribute mainly to the second principal component. The second component describes mainly the differences between the alkali treated and untreated samples independently of the washing. These differences can be explained mainly by the effect of alkaline treatments on the structure of hemicellulose component of hemp.

In the second evaluation the integrated intensities of mass spectrometric ions have been used. It can be seen in Figs. 5c-d that $60.0 \%$ and $18.8 \%$ of the total variance was described by factor 1 and factor 2, respectively. The first component separates the alkali-treated samples from the others, whereas the second component separates the washed samples from the untreated samples. The loading plot reveals that the yields of $\mathrm{CO}$, furanone, methane, water as well as potassium and sodium ion contents play the most significant role in determining the first principal component. The increased $\mathrm{K}^{+}$and $\mathrm{Na}^{+}$content of the samples leads to enhanced methane, water and carbon-monoxide formation as well as to reduced formaldehyde evolution. The $\mathrm{m} / \mathrm{z}, 60$ and 44 ions (acetic acid and $\mathrm{CO}_{2}$ ) contribute mostly to the second principal component, which is different mostly between the untreated and other samples. 

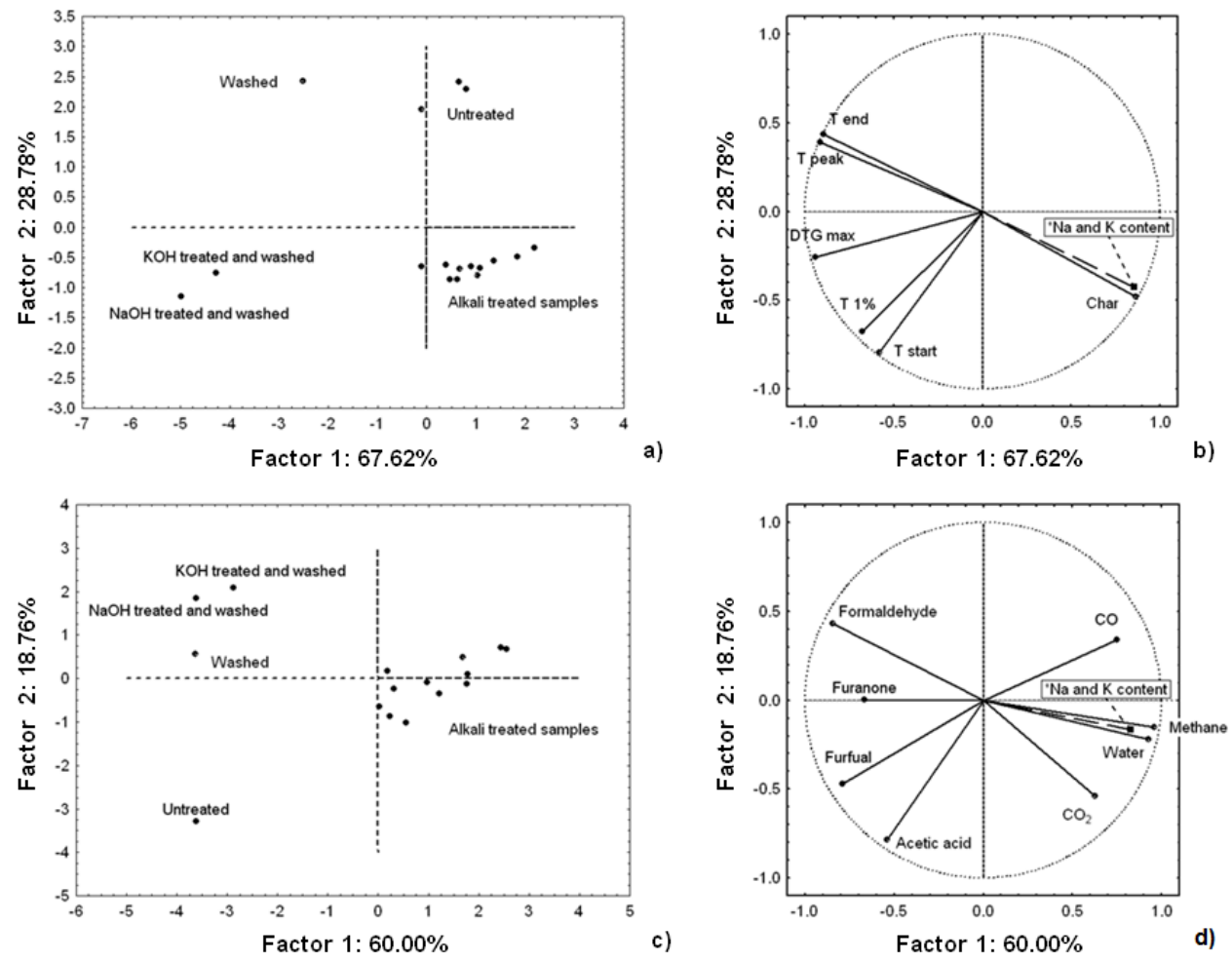

Fig. 5 Results of the principal component analysis: score and loading plots based on a - b thermogravimetric parameters, $\mathrm{c}-\mathrm{d}$ - mass spectrometric intensities of the selected ions

\section{Conclusions}

Thermal decomposition of untreated, washed and various alkaline pretreated hemp samples was measured by TG/MS analytical method. The alkali ion contents of the samples were determined by ICP-OES system. The obtained data have been evaluated by principal component analysis. As a result of the PCA, the washed, untreated and treated-washed samples were separated from the alkali treated hemp samples. We concluded that the alkaline pretreatment caused two major effects on the decomposition of the samples. On the one hand, chemical changes occurred mainly in the hemicellulose component of hemp: the acetyl groups were apparently removed by the alkaline treatment. Thus the thermal decomposition of the hemicellulose component shifted to higher temperature in the alkali-treated samples. On the other hand, the residual sodium and potassium ions exhibit substantial impact on the thermal decomposition. We established that the amount of the sodium and potassium ions determine the extent of the effect. The largest alteration of the TG/MS parameters can be observed in the 0-0.2 mmol $\mathrm{g}^{-1}$ concentration range of the alkali ions. The DTG parameters characteristic of the cellulose decomposition ( $T_{\text {peak }}, T_{\text {end }}$ ) show the most prominent correlation with the sodium and potassium content of the samples confirming the fact that cellulose decomposition is highly sensitive for the presence of alkali ions. The yield of the char residue as well as the evolution of water and methane increased, while the formation of higher molecular mass products (acetic acid, furanone, furfural) decreased in the case of alkaline treated samples. 


\section{Acknowledgements}

This work was supported by the Hungarian National Research Fund (OTKA K61504, K81959, K72710 and PD75740). The authors are grateful to Dr. Gábor Várhegyi for data analysis programs.

\section{References}

1. Pracella M, Chionna D, Anguillesi I, Kulinski Z, Piorkowska E. Functionalization, compatibilization and properties of polypropylene composites with hemp fibres. Compos Sci Technol 2006;66:2218-30

2. Placet V. Characterization of the thermo-mechanical behaviour of hemp fibres intended for the manufacturing of high performance composites. Compos Part A 2009;40:1111-8

3. Heikkinen JM, Hordijk JC, de Jong W, Spliethoff H. Thermogravimetry as a tool to classify waste components to be used for energy generation. J Anal Appl Pyrolysis 2004;71:883-900

4. Garcia-Jaldon C, Dupeyre D, Vignon MR. Fibres from semi-retted hemp bundles by steam explosion treatment. Biomass Bioenergy 1998;14:251-60

5. van der Wert HMG, van der Veen JEH, Bouma ATM, ten Cate M. Quality of hemp (Cannabis sativa L.) stems as a raw material for paper. Ind Crop Prod 1994;2:219-27

6. Ouajai S, Shanks RA. Composition, structure and thermal degradation of hemp cellulose after chemical treatments. Polym Degrad Stab 2005;89:327-35

7. Kadar Z, Szengyel Z, Reczey K. Simultaneous saccharification and fermentation (SSF) of industrial wastes for the production of ethanol. Ind Crop Prod 2004;20:103-10

8. Lee J. Biological conversion of lignocellulosic biomass to ethanol. J Biotechnol 1997;56:1-24

9. Meszaros E, Jakab E, Gaspar M, Reczey K, Varhegyi G. Thermal behavior of corn fibers and corn fiber gums prepared in fiber processing to ethanol. J Anal Appl Pyrolysis 2009;85:11-8

10. Sun R, Lawther JM, Banks WB. Influence of alkaline pre-treatments on the cell wall components wheat straw. Ind Crop Prod 1995;4:127-45

11. Le Troedec M, Sedan D, Peyratout C, Bonnet JP, Smith A, Guinebretiere R, Gloaguen V, Krausz P. Influence of various chemical treatments on the composition and structure of hemp fibres. Compos Part A 2008;39:514-22

12. Ballesteros M, Olivia JM, Negro MJ, Manzanares P, Ballesteros I. Ethanol from lignocellulosic materials by a simultaneous saccharification and fermentation process (SFS) with Kluyveromyces marxianus CECT 10875. Process Biochem 2004;39:1843-8

13. Cantarella M, Cantarella L, Gallifuoco A, Spera A, Alfani F. Comparison of different detoxification methods for steam-exploded poplar wood as a substrate for the bioproduction of ethanol in SHF and SSF. Process Biochem 2004;39:1533-42

14. Buryan P, Staff M. Pyrolysis of waste biomass. J Therm Anal Calorim 2008;93:637-40

15. Meszaros E, Jakab E, Varhegyi G, Tovari P. Thermogravimetry/mass spectrometry analysis of energy crops. J Therm Anal Calorim 2007;88:477-82

16. Meszaros E, Jakab E, Varhegyi G, Szepesvary P, Marosvolgyi B. Comparative study of the thermal behavior of wood and bark of young shoots obtained from an energy plantation. J Anal Appl Pyrolysis 2004;72:317-28

17. Streibel T, Geissler R, Saraji-Bozorgzad M, Sklorz M, Kaisersberger E, Denner T, Zimmermann R. Evolved gas analysis (EGA) in TG and DSC with single photon ionisation mass spectrometry (SPI-MS): molecular organic signatures from pyrolysis of soft and hard wood, coal, crude oil and ABS polymer. J Therm Anal Calorim 2009;96:795-804

18. Streibel T, Fendt A, Geissler R, Kaisersberger E, Denner T, Zimmermann R. Thermal analysis/mass spectrometry using soft photo-ionisation for the investigation of biomass and mineral oils. J Therm Anal Calorim 2009;97:615-9

19. Mothe CG, de Miranda IC. Characterization of sugarcane and coconut fibers by thermal analysis and FTIR. J Therm Anal Calorim 2009;97:661-5

20. Souza BS, Moreira APD, Teixeira AMFR. TG-FTIR coupling to monitor the pyrolysis products from agricultural residues. J Therm Anal Calorim 2009;97:637-42

21. Shafizadeh F. pyrolysis and combustion of cellulosic materials. Adv Carbohydr Chem Biochem 1968;23:419-74 
22. Bridgwater AV. Fast pyrolysis of biomass: a handbook. Vol. 2. CPL Press; 2002.

23. Meier D, Faix O. State of the art of applied fast pyrolysis of lignocellulosic materials - a review. Bioresour Technol 1999;68:71-7

24. Antal MJ Jr, Varhegyi G. Cellulose pyrolysis kinetics: the current state of knowledge. Ind Eng Chem Resour 1995;34:703-17

25. DeGroot WF, Shafizadeh F. The influence of exchangeable cations on the carbonization of biomass. J Anal Appl Pyrolysis 1984;6:217-32

26. Sekiguchi Y, Shafizadeh F. The effect of inorganic additives on the formation, composition, and combustion of cellulosic char. J Appl Polym Sci 1984;29:1267-86

27. Varhegyi G, Antal MJ Jr, Szekely T, Till F, Jakab E. Simultaneous thermogravimetricmass spectrometric studies of the thermal decomposition of biopolymers. 1. avicel cellulose in the presence and absence of catalysts. Energy Fuel 1988;2:267-72

28. Khelfa A, Finqueneisel G, Auber M, Weber JV. Influence of some minerals on the cellulose thermal degradation mechanism - Thermogravimetric and pyrolysis-mass spectrometry studies. J Therm Anal Calorim 2008;92:795-9

29. Dobele G, Rossinskaja G, Dizhbite T, Telysheva G, Meier D, Faix O. Application of catalysts for obtaining 1,6-anhydrosaccharides from cellulose and wood by fast pyrolysis J Anal Appl Pyrolysis 2005;74:401-5

30. Torri C, Lesci IG, Fabbri D. Analytical study on the production of a hydroxylactone from catalytic pyrolysis of carbohydrates with nanopowder aluminium titanate. J Anal Appl Pyrolysis 2009;84:25-30

31. Nowakowski DJ, Jones JM. Uncatalysed and potassium-catalysed pyrolysis of the cellwall constituents of biomass and their model compounds. J Anal Appl Pyrolysis 2008;83:12-25

32. Shimada N, Kawamoto H, Saka S. Different action of alkali/alkaline earth metal chlorides on cellulose pyrolysis. J Anal Appl Pyrolysis 2008;81:80-7

33. Ren QQ, Zhao CS, Wu X, Liang C, Chen XP, Shen JZ, Wang Z. Catalytic effect of Fe, Al and $\mathrm{Si}$ on the formation of $\mathrm{NO}_{\mathrm{x}}$ precursors and $\mathrm{HCl}$ during straw pyrolysis. J Therm Anal Calorim 2010;99:301-6

34. Jakab E, Faix O, Till F, Szekely T. The effect of cations on the thermal decomposition of lignins. J Anal Appl Pyrolysis 1993;25:185-94

35. Jakab E, Faix O, Till F. Thermal decomposition of milled wood lignins studied by thermogravimetry/mass spectrometry. J Anal Appl Pyrolysis 1997;40-41:171-86

36. Rachini A, Le Troedec M, Peyratout C, Smith A. Comparison of the thermal degradation of natural, alkali-treated and silane-treated hemp fibers under air and inert atmosphere. $\mathrm{J}$ Appl Polym Sci 2009;112:226-34

37. del Rio JC, Martinez AT, Gutierrez A, Presence of 5-hydroxyguaiacyl units as native lignin constituents in plants as seen by Py-GC/MS. J Anal Appl Pyrolysis 2007;79:33-8

38. del Rio JC, Gutierrez A, Rodriguez IM, Ibarra D, Martinez AT. Composition of nonwoody plant lignins and cinnamic acids by Py-GC/MS, Py/TMAH and FTIR. J Anal Appl Pyrolysis 2007;79:39-46

39. Gutierrez A, Rodriguez IM, del Rio JC. Chemical Characterization of lignin and lipid fractions in industrial hemp bast fibers used for manufacturing high-quality paper pulp. J Agric Food Chem 2006;54:2138-44

40. Kristensen R, Coulson S, Gordon A. THM PyGC-MS of wood fragment and vegetable fibre forencic samples. J Anal Appl Pyrolysis 2009;86:90-8

41. Szabo P, Varhegyi G, Till F, Faix O. Thermogravimetric/mass spectrometric characterization of two energy crops, Arundo donax and Miscanthus sinensis. J Anal Appl Pyrolysis 1996;36:179-90

42. Sebestyen Z. Alkali pretreatment of hemp with the goal of bioethanol production. Master's Thesis 2008

43. Jakab E, Liu K, Meuzelaar HLC. Thermal decomposition of wood and cellulose in the presence of solvent vapors. Ind Eng Chem Resour 1997;36:2087-95 